\title{
Logística no Modal Rodoviário: \\ Uma abordagem de custos em função da distância de transporte e tipo de veículo
}

\author{
Logistics in the Road Modal: \\ A costs approach in function of the distance of \\ transport and type of vehicle
}

\author{
Mario Cesar Stamm Junior'; ${ }^{1}$ Thiago Epiphanio Pereira ${ }^{2}$
}

\begin{abstract}
Resumo
Com o aumento da produção da soja nos últimos anos, transportada em sua grande maioria pelo modal rodoviário, o Brasil vem encontrando grandes barreiras no escoamento dessa oleaginosa, principalmente, devido à falta de infra-estrutura e à situação precária em que se encontram atualmente muitas das rodovias brasileiras. Esses fatores influenciam diretamente os custos com transporte e, conseqüentemente, custos logísticos, que, por sua vez, participam de maneira expressiva no custo total da soja brasileira. No presente trabalho, com o intuito de se otimizar e controlar com maior eficiência os custos no transporte rodoviário da soja, realizou-se simulações de percursos com os principais veículos para o transporte rodoviário de soja no Estado do Paraná, sendo estes: veiculo 1 - semi-reboque graneleiro, veículo 2 - bitrem graneleiro e veículo 3 - rodotrem graneleiro. Além dessas simulações, foram feitas análises pormenorizadas dos custos de cada veículo, que mostrou o rodotrem graneleiro muito superior que os demais, tanto em capacidade, chegando a uma superioridade de $67 \%$, como em custos, apresentando uma economia de até $29 \%$, sendo economicamente mais indicado para transporte de carga a granel.

Palavras-chave: Logística. Transportes. Custos de Transporte Rodoviário.
\end{abstract}

\begin{abstract}
With the increase in soybean production in the last couple of years - transported mostly by road - Brazil has faced great transportation problems, mainly due to lack of infrastructure and poor road conditions. These factors have direct influence on transportation costs and, consequently, on logistics costs, strongly affecting the final cost of soybean in Brazil. In this work, a simulation with different routes and main road carriers was carried out aiming at optimizing and controlling soybean ground transportation more efficiently in the State of Paraná. The following road carriers used for soybean ground transportation in the State of Paraná were analyzed: vehicle 1 - a semi-trailer truck, vehicle 2 - a bitrem ( truck with interlinked trailers ) and vehicle 3 - a rodotrem (truck with two large trailers). A detailed cost analysis for each vehicle showed that vehicle 3 - the rodotrem- was superior in both capacity and costeffectiveness, reaching $67 \%$ more capacity and $29 \%$ less costs in comparison to the others, thus being the most recommended for grain transportation.
\end{abstract}

Key words: Logistics. Transportation. Road Transportation Costs.

1 Doutor em Engenharia de Transportes, Professor da Universidade Estadual de Londrina; E-mail: mario.stamm@gmail.com Aluno do $5^{\circ}$. Ano do Curso de Engenharia Civil, Universidade Estadual de Londrina - E-mail: thiago.epiphanio@gmail.com 


\section{Introdução}

A soja é o principal commodity brasileiro e tem estado em grande evidência tanto em âmbito nacional como internacional. Sua importância para a economia do Brasil é incontestável, principalmente, por ser um dos principais produtos de exportação brasileira, gerando receitas significativas tanto para o Estado do Paraná, como para a União, além de ser responsável por uma parte considerável do PIB.

O modal rodoviário chama atenção devido a sua enorme variabilidade e flexibilidade, tanto de trajetos como de veículos, o que o torna mais complexo e difícil de se equalizar. No Brasil, este modal apresenta-se desenvolvido de maneira extremamente abrangente na matriz de transportes, sendo responsável, de acordo com a Agência Nacional de Transporte Terrestre - ANTT (2006), por quase dois terços de tudo que se transporta no país, $60 \%$ das cargas transportadas em 2005 , o que o torna o maior do país e dá-lhe um papel de extrema importancia no transporte de cargas. O mesmo ocorre dentro da estrutura de transportes do Estado do Paraná.

De acordo com o United States Department of Agriculture - USDA (2006), o Brasil se encontra como o segundo maior produtor de soja mundial, e a sua produção vem aumentando consideravelmente no decorrer dos últimos anos. Com isso, o escoamento desse produto vem encontrando barreiras, principalmente, devido à falta de infraestrutura de transportes no país.

Um dos principais pontos a serem considerados na análise de custos com transporte de carga no Brasil é a ineficiente distribuição dos seus modais, além de uma infra-estrutura de transportes precária. As vantagens competitivas da produção de soja no Brasil se dissolvem significativamente depois de computados custos dos modais de transporte, armazenamento e custos portuários.Para se transportar uma tonelada de grãos de soja da fazenda até o porto no Brasil, o produtor gasta em torno de US\$28,00 por tonelada. Já nos EUA, como comparação, este custo cai para
US $\$ 15,00$ por tonelada, uma redução de $87 \%$ em relação ao preço brasileiro (BOZZA; DIGIOVANI, 2004). Isso se deve, principalmente, a alta infraestrutura de transportes americana, o que constitui uma das principais vantagens competitivas em relação ao Brasil e a Argentina na produção agrícola e no mercado.

Um outro diferencial diz respeito às despesas portuárias, com custo de US\$3,00/tonelada no EUA, enquanto no Brasil o custo é de US\$ 6,00/ tonelada, isto é, em torno de 50\% maior (BOZZA; DIGIOVANI, 2004).

Conforme dados da Associação Nacional do Transporte de Cargas e Logística - NTC (2006), o setor compreende 12 mil empresas transportadoras, sendo $95 \%$ destas de pequeno e médio porte. Também fazem parte deste segmento no Brasil, mais de 350.000 transportadores autônomos, que, juntamente com as transportadoras ofertam serviços de transporte rodoviário de cargas.

Isso tudo dá a dimensão da importância que tem o modal rodoviário na economia nacional e reforça a necessidade de estudos mais minuciosas acerca das possibilidades existentes dentro deste modal com a combinação de diferentes tipos de veículos e com a variação da distância de transporte.

\section{Objetivo}

Desenvolver estudo comparativo entre custos de transporte do modal rodoviário no transporte da soja em grão em função de diferentes distâncias e tipos de veículos.

\section{Metodologia}

O cálculo dos custos de transporte rodoviário foi realizado com base na estruturação de custos disposta no Manual de Cálculo de Custos e Formação de Preços do Transporte Rodoviário de Cargas (ASSOCIAÇÃO NACIONAL DO TRANSPORTE DE CARGAS - NTC, 2001). 
Os valores dos insumos de custos ${ }^{3}$ foram obtidos por meio de cotações com revendedoras de veículos e equipamentos para o transporte rodoviário de cargas, pesquisas realizadas na internet e contatos diretos com empresas operadoras do setor rodoviário de cargas.

Foram calculados os custos de transporte para três veículos diferentes de transporte rodoviário de carga a granel: o semi-reboque graneleiro, o bi-trem graneleiro e o rodotrem graneleiro.

Para cada um dos veículos foram feitas simulações de percursos em três faixas distintas de quilometragem: $200 \mathrm{~km}, 400 \mathrm{~km}$ e $600 \mathrm{~km}$.

Os percursos foram escolhidos passando pelos principais eixos rodoviários do Paraná, onde se encontram instaladas praças de pedágio.

\section{Cálculo do custo de transporte}

O cálculo do custo de transporte foi realizado tendo como base a estruturação de custos disposta no Manual de Cálculo de Custos e Formação de Preços do Transporte Rodoviário de Cargas (NTC, 2001), considerando-se os seguintes custos : custos fixos, custos variáveis, despesas indiretas (ou administrativas e de terminais) e custos com pedágio.

\section{Custos fixos}

Os custos fixos correspondem às despesas operacionais do veículo que não variam com a distância percorrida, isto é, continuam existindo, mesmo com o veículo parado. Geralmente, são calculados por mês.

O custo fixo é composto das seguintes parcelas;

- Remuneração mensal do capital empatado

- Salário do motorista

\footnotetext{
3 Valores obtidos através de pesquisas realizadas durante setembro de 2006 .
}

- Salário de oficina

- Reposição do veículo

- Reposição do equipamento

- Licenciamento

- Seguro do veículo

- Seguro do equipamento

- Seguro de responsabilidade civil facultativo

\section{Custos variáveis}

Correspondem a despesas que variam com a distância percorrida pelo veículo, ou seja, que inexistem caso o veículo permaneça parado.

O custo variável é composto das seguintes parcelas:

- Remuneração mensal do capital empatado

- Despesas com combustível

- Lubrificantes

- Lavagem e graxas

- Pneus e recauchutagens

\section{Despesas indiretas}

As despesas indiretas ou despesas administrativas e de terminais são aquelas que não estão relacionadas diretamente com a operação do veículo. Não variam, portanto, com a quilometragem rodada, mas sim com a tonelagem movimentada.

\section{Custos com pedágio}

As despesas com pedágio foram computadas de acordo com os valores fornecidos pelas concessionárias de pedágio no Paraná (DEPARTAMENTO DE ESTRADAS DE RODAGEM DO PARANÁ - DER, 2006) e com a rota escolhida. 


\section{Considerações para cálculo}

Os veículos considerados foram novos e próprios para o transporte de soja pelo modal rodoviário, e cada veículo era formado pela combinação de um cavalo mecânico (truck) e uma carreta de carga (trailler).

A seguir são apresentadas as principais características dos três veículos usados neste trabalho: veiculo 1 - semi-reboque graneleiro; veículo 2 - bitrem graneleiro; e veículo 3 - rodotrem graneleiro.

\section{Veículo 1}

O veículo 1 é composto por um cavalo mecânico $4 \times 2$ e uma carreta semi-reboque graneleira, cujos dados e características estão descritos nas Tabelas 1 e 2 .

\section{Veículo 2}

O veículo 1 é composto por um cavalo mecânico $6 \times 4$ e uma carreta bitrem graneleira, cujos dados e características são apresentados nas Tabelas 3 e 4.

Tabela 1. Características e dados sobre cavalo mecânico 4 x 2 .

\begin{tabular}{|c|c|c|}
\hline Modelo & \multicolumn{2}{|c|}{ Cavalo mecânico 4 X 2} \\
\hline Motor & \multicolumn{2}{|c|}{ OM-457 LA.III/22 $349 \mathrm{cv}$ a $1900 \mathrm{rpm}$} \\
\hline PBT & $16.000,00$ & $\mathrm{~kg}$ \\
\hline PBTC & $45.000,00$ & $\mathrm{~kg}$ \\
\hline Tipo de pneus & \multicolumn{2}{|c|}{$295 / 80$ R 22,5} \\
\hline Quantidade de pneus & 6 & unid \\
\hline Número de eixos & 2 & unid \\
\hline Preço unitário dos pneus & $1.293,00$ & $\mathrm{R} \$$ \\
\hline Preço total dos pneus & $7.758,00$ & $\mathrm{R} \$$ \\
\hline Preço do veículo sem pneus & $269.280,19$ & $\mathrm{R} \$$ \\
\hline Preço do veículo com pneus & $277.038,19$ & $\mathrm{R} \$$ \\
\hline
\end{tabular}

Tabela 2. Características e dados sobre carreta semi-reboque graneleira.

\begin{tabular}{|l|l|l|}
\hline \multicolumn{1}{|c|}{ Modelo } & \multicolumn{2}{c|}{ Carreta semi-reboque graneleira } \\
\hline Capacidade de carga & $29.200,00$ & $\mathrm{~kg}$ \\
\hline Tara & $7.800,00$ & $\mathrm{~kg}$ \\
\hline PBT & $37.000,00$ & $\mathrm{~kg}$ \\
\hline PBTC & $44.500,00$ & $\mathrm{~kg}$ \\
\hline Tipo de pneus & $295 / 80 \mathrm{R} 22,5$ & \multicolumn{2}{l|}{} \\
\hline Quantidade de pneus & 12 & unid \\
\hline Número de eixos & 3 & unid \\
\hline Preço unitário dos pneus & $1.293,00$ & $\mathrm{R} \$$ \\
\hline Preço total dos pneus & $15.516,00$ & $\mathrm{R} \$$ \\
\hline Preço do equipamento sem pneus & $34.484,00$ & $\mathrm{R} \$$ \\
\hline Preço do equipamento com pneus & $50.000,00$ & $\mathrm{R} \$$ \\
\hline
\end{tabular}


Tabela 3. Características e dados sobre cavalo mecânico 6 x 2 .

\begin{tabular}{|l|l|l|}
\hline \multicolumn{1}{|c|}{ Modelo } & \multicolumn{2}{c|}{ Cavalo mecânico 6 X 2 } \\
\hline Motor & OM-457 LA.III/23 401 cv a 1900 rpm \\
\hline PBT & $30.100,00$ & $\mathrm{~kg}$ \\
\hline PBTC & $57.000,00$ & $\mathrm{~kg}$ \\
\hline Tipo de pneus & $295 / 80 \mathrm{R} 22,5$ & \multicolumn{2}{l|}{} \\
\hline Quantidade de pneus & 10 & unid \\
\hline Número de eixos & 3 & unid \\
\hline Preço unitário dos pneus & $1.293,00$ & $\mathrm{R} \$$ \\
\hline Preço total dos pneus & $12.930,00$ & $\mathrm{R} \$$ \\
\hline Preço do veículo sem pneus & $323.198,81$ & $\mathrm{R} \$$ \\
\hline Preço do veículo com pneus & $336.128,81$ & $\mathrm{R} \$$ \\
\hline
\end{tabular}

Tabela 4. Características e dados sobre carreta bitrem graneleira.

\begin{tabular}{|l|l|l|}
\hline \multicolumn{1}{|c|}{ Modelo } & \multicolumn{2}{c|}{ Carreta bitrem graneleira } \\
\hline Capacidade de carga & $37.510,00$ & $\mathrm{~kg}$ \\
\hline Tara & $10.990,00$ & $\mathrm{~kg}$ \\
\hline PBT & $48.500,00$ & $\mathrm{~kg}$ \\
\hline PBTC & $57.000,00$ & $\mathrm{~kg}$ \\
\hline Tipo de pneus & $295 / 80 \mathrm{R} 22,5$ & \multicolumn{2}{l|}{} \\
\hline Quantidade de pneus & 16 & unid \\
\hline Número de eixos & 4 & $\mathrm{Unid}$ \\
\hline Preço unitário dos pneus & $1.293,00$ & $\mathrm{R} \$$ \\
\hline Preço total dos pneus & $20.688,00$ & $\mathrm{R} \$$ \\
\hline Preço do equipamento sem pneus & $51.812,00$ & $\mathrm{R} \$$ \\
\hline Preço do equipamento com pneus & $72.500,00$ & $\mathrm{R} \$$ \\
\hline
\end{tabular}

\section{Veículo 3}

O veículo 3 é composto por um cavalo mecânico $6 \times 2$ e uma carreta rodotrem graneleira, cujo dados e características são apresentados nas Tabelas 5 e 6 . 
Tabela 5. Características e dados sobre cavalo mecânico 6 x 4 .

\begin{tabular}{|l|l|l|}
\hline \multicolumn{1}{|c|}{ Modelo } & \multicolumn{2}{c|}{ Cavalo mecânico 6 X 4 } \\
\hline Motor & OM-457 LA.III/24 428 cv a 1900 rpm \\
\hline PBT & $23.000,00$ & $\mathrm{~kg}$ \\
\hline PBTC & $74.000,00$ & $\mathrm{~kg}$ \\
\hline Tipo de pneus & $295 / 80 \mathrm{R} 22,5$ & \multicolumn{2}{l|}{} \\
\hline Quantidade de pneus & 10 & unid \\
\hline Número de eixos & 3 & unid \\
\hline Preço unitário dos pneus & $1.293,00$ & $\mathrm{R} \$$ \\
\hline Preço total dos pneus & $12.930,00$ & $\mathrm{R} \$$ \\
\hline Preço veículo sem pneus & $377.126,32$ & $\mathrm{R} \$$ \\
\hline Preço veículo com pneus & $390.056,32$ & $\mathrm{R} \$$ \\
\hline
\end{tabular}

Tabela 6. Características e dados sobre carreta rodotrem graneleira.

\begin{tabular}{|l|l|l|}
\hline \multicolumn{1}{|c|}{ Modelo } & \multicolumn{2}{c|}{ Carreta rodotrem graneleira } \\
\hline Capacidade de carga & $48.880,00$ & $\mathrm{~kg}$ \\
\hline Tara & $15.620,00$ & $\mathrm{~kg}$ \\
\hline PBT & $64.500,00$ & $\mathrm{~kg}$ \\
\hline PBTC & $74.000,00$ & $\mathrm{~kg}$ \\
\hline Tipo de pneus & $295 / 80 \mathrm{R} 22,6$ & \multicolumn{2}{l|}{} \\
\hline Quantidade de pneus & 24 & unid \\
\hline Número de eixos & 6 & unid \\
\hline Preço unitário dos pneus & $1.293,00$ & $\mathrm{R} \$$ \\
\hline Preço total dos pneus & $31.032,00$ & $\mathrm{R} \$$ \\
\hline Preço do equipamento sem pneus & $88.968,00$ & $\mathrm{R} \$$ \\
\hline Preço do equipamento com pneus & $120.000,00$ & $\mathrm{R} \$$ \\
\hline
\end{tabular}

\section{Análises de percursos}

Foram feitas simulações com os três veículos em três faixas de quilometragem diferentes, 200 $\mathrm{km}, 400 \mathrm{~km}$ e $600 \mathrm{~km}$. Para isso foram escolhidos três pontos importantes no Estado do Paraná que correspondessem a essas quilometragens, todos esses pontos foram destinados para o porto de Paranaguá, principal porto do Paraná e muito importante para o escoamento de soja no país. Os percursos escolhidos levam em conta também os principais eixos de transporte rodoviário, podendo assim ser analisados a influência dos pedágios nos custos totais. As cidades escolhidas foram Cascavel, Mauá da Serra e Ponta Grossa, e podem ser vistas na figura seguinte com os seus respectivos percursos. 


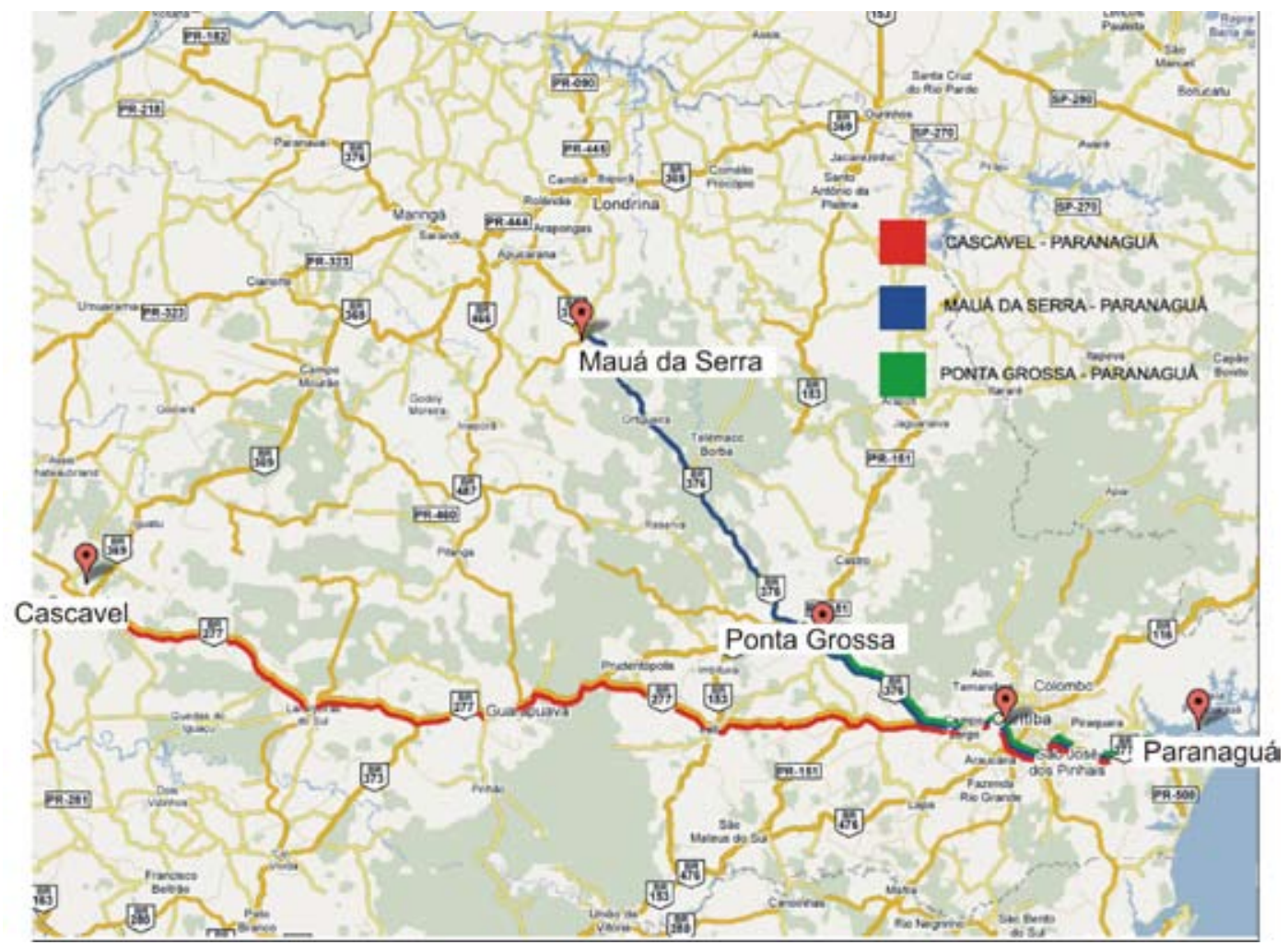

Figura 1. Percursos escolhidos para simulações no Estado do Paraná.

A primeira análise de percurso, trecho entre Cascavel e Paranaguá, mostra um incremento de $41,3 \%$ nos custos totais por tonelada do veículo 1 em relação aos custos do veículo 3 e de $18,2 \%$ em relação ao veículo 2 . O veículo 2 também apresenta incremento de 19,6\% em relação ao veículo 3 para os custos totais por tonelada. Dessa forma, temse estabelecida uma ordem classificatória entre os veículos, com o veículo 1 apresentando os maiores valores de custo total por tonelada, seguido do veículo 2 e do veículo 3 .

No caso dos custos fixos por tonelada, custos variáveis por tonelada e despesas indiretas por tonelada os três veículos analisados classificamse obedecendo à mesma ordem classificatória apresentada em relação aos custos totais por tonelada, apresentando somente variações de grandezas nas relações entre eles, conforme pode-se observar nos valores apresentados na Figura 2.

A exceção ocorre nos custos de pedágio por tonelada. O aumento de custos devido ao aumento da quantidade de eixos no veículo não é proporcional à redução de custos causada por um aumento de sua capacidade, fazendo com que os custos de pedágio por tonelada se comportem de maneira diferente: o veículo 1 é o que apresenta menores custos de pedágio por tonelada, seguido pelo veículo 3 e por último pelo veículo 2 .

Os custos totais por tonelada por quilômetro resultantes desta análise são de $\mathrm{R} \$ 0,136, \mathrm{R} \$ 0,115$ e de $\mathrm{R} \$ 0,096$, respectivamente, para os veículos 1 , 2 e 3, e suas respectivas capacidades de transporte por mês são de 262,8 toneladas, 337,59 toneladas e 439,32 toneladas. 
CASCAVEL - PARANAGUA 594 km

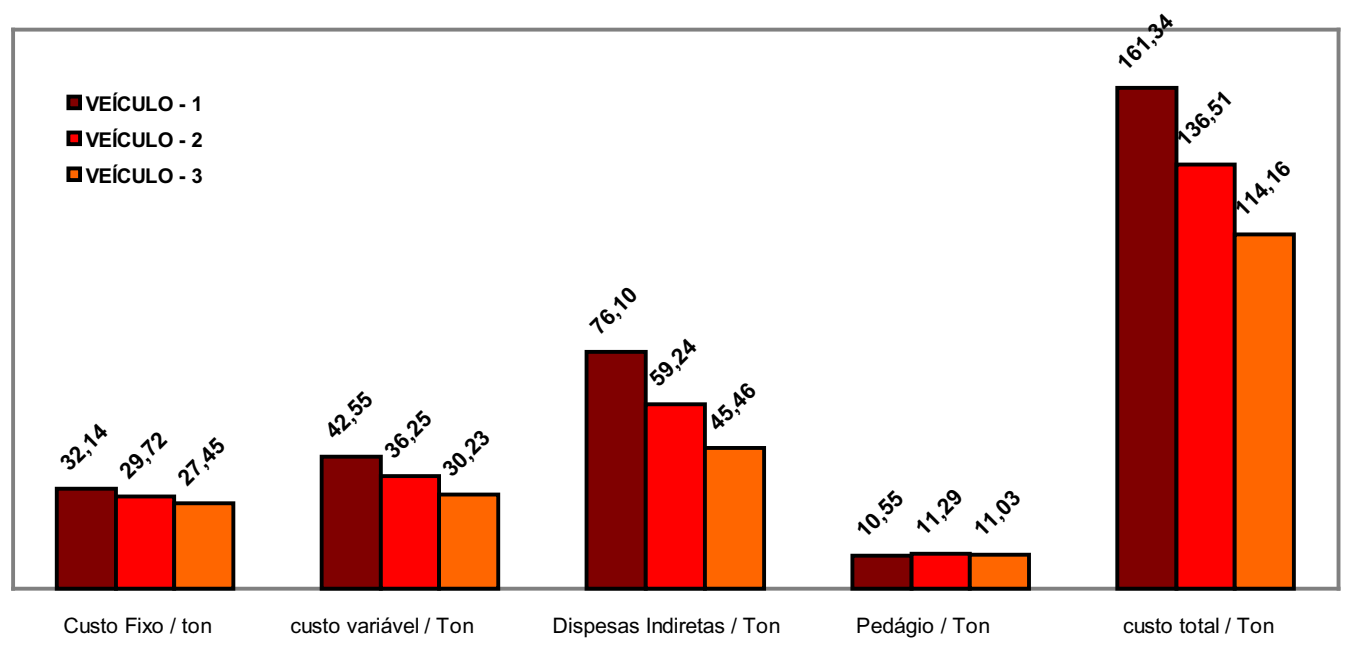

Figura 2. Custo por tonelada transportada no trecho entre Cascavel - Paranaguá.

$\mathrm{Na}$ segunda análise de percurso, trecho entre Mauá da Serra e Paranaguá, pode-se observar um aumento de 40,9\% no custo total por tonelada do veículo 1 , em relação ao custo total por tonelada do veículo 3 e de 17,9\% em relação ao veículo 2 . $\mathrm{O}$ veículo 2 também apresenta um incremento de 19,4\% em relação ao veículo 3 para os custos totais por tonelada. Dessa forma, tem-se estabelecida uma ordem classificatória entre os veículos, com o veículo 1 apresentando os maiores valores de custo total por tonelada, seguido do veículo 2 e do veículo 3 , como no caso anterior.

No caso dos custos fixos por tonelada, custos variáveis por tonelada e despesas indiretas por tonelada os três veículos analisados classificamse obedecendo à mesma ordem classificatória apresentada em relação aos custos totais por tonelada, apresentando somente variações de grandezas nas relações entre eles, a exemplo do caso anterior, conforme se pode observar nos valores apresentados na Figura 3.

Os custos com pedágio nesse caso também se comportam de maneira diferente, como visto na primeira análise.

O custo total médio deste caso é de $69,3 \%$ dos custos totais por tonelada do primeiro caso, devido à redução do percurso.

Os custos por tonelada por quilômetro da segunda análise são de $\mathrm{R} \$ 0,140, \mathrm{R} \$ 0,119$ e de $\mathrm{R} \$ 0,099$ respectivamente para os veículos 1, 2 e 3, e suas respectivas capacidades de transporte por mês são de 379,60 toneladas, 487,63 toneladas e 635,44 toneladas. 
MAUÁ DA SERRA - PARANAGUÁ 400,5km

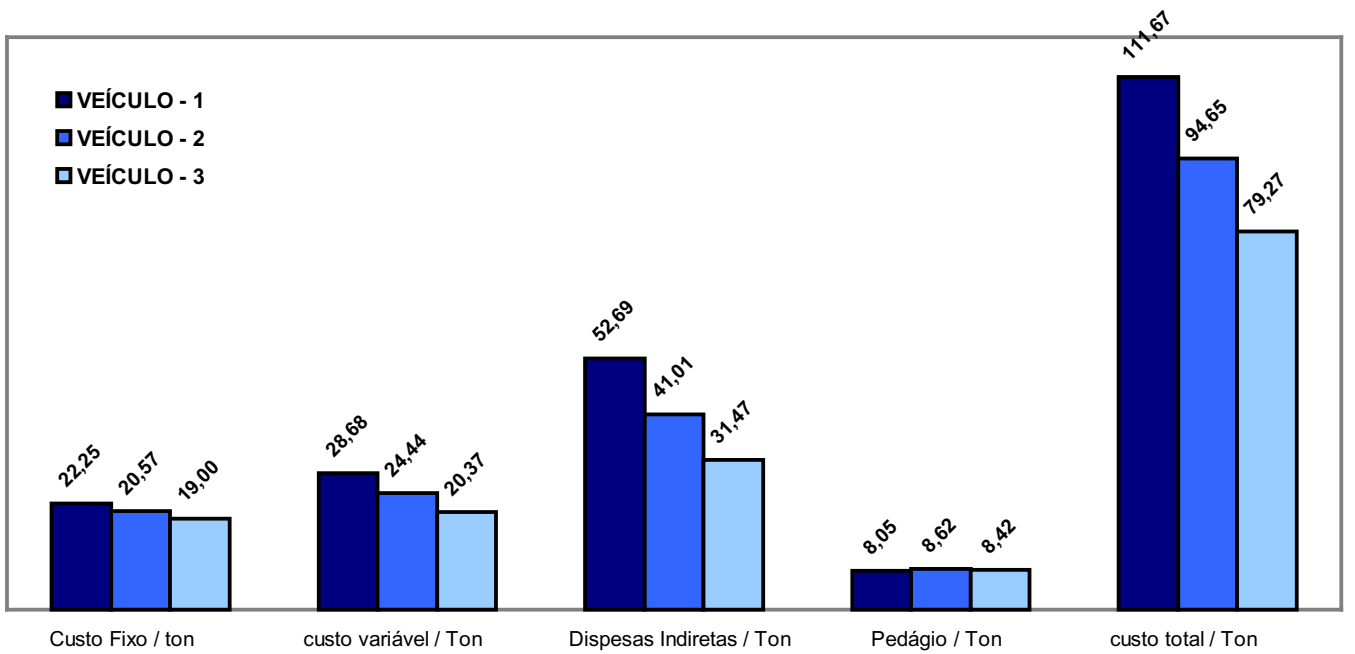

Figura 3. Custo por tonelada transportada no trecho entre Mauá da Serra - Paranaguá.

$\mathrm{Na}$ terceira e última análise de percurso, trecho entre Ponta Grossa e Paranaguá, observa-se um incremento de aproximadamente $42,0 \%$ nos custos totais por tonelada do veículo 1 em comparação com o veículo 3 e de $18,6 \%$ em relação ao veículo 2 . O veículo 2 também apresenta incremento de 19,8\%, em relação ao veículo 3 para os custos totais, por tonelada. Dessa forma, tem-se estabelecida uma ordem classificatória entre os veículos, com o veículo 1 apresentando os maiores valores de custo total por tonelada, seguido do veículo 2 e do veículo 3 , como nos dois casos anteriores.

No caso dos custos fixos por tonelada, custos variáveis por tonelada e despesas indiretas por tonelada os três veículos analisados classificamse obedecendo à mesma ordem classificatória apresentada em relação aos custos totais por tonelada, apresentando somente variações de grandezas nas relações entre eles, a exemplo dos casos anteriores, conforme pode-se observar nos valores apresentados na Figura 4.

Os custos com pedágio neste caso também se comportam de maneira diferente, como visto nas duas análises anteriores.

O valor do custo total médio por tonelada é de $40,3 \%$ dos custos totais por tonelada do primeiro caso, e de $58,1 \%$ dos custos totais no segundo caso, isso ocorre também em função da redução da distância percorrida pelo veículo.

Os custos por tonelada por quilômetro da última análise são de $\mathrm{R} \$ 0,157, \mathrm{R} \$ 0,133$ e de $\mathrm{R} \$ 0,111$ respectivamente para os veículos 1,2 e 3 , e suas respectivas capacidades de transporte por mês são de 613,20 toneladas, 787,71 toneladas e 1.026,48 toneladas. 


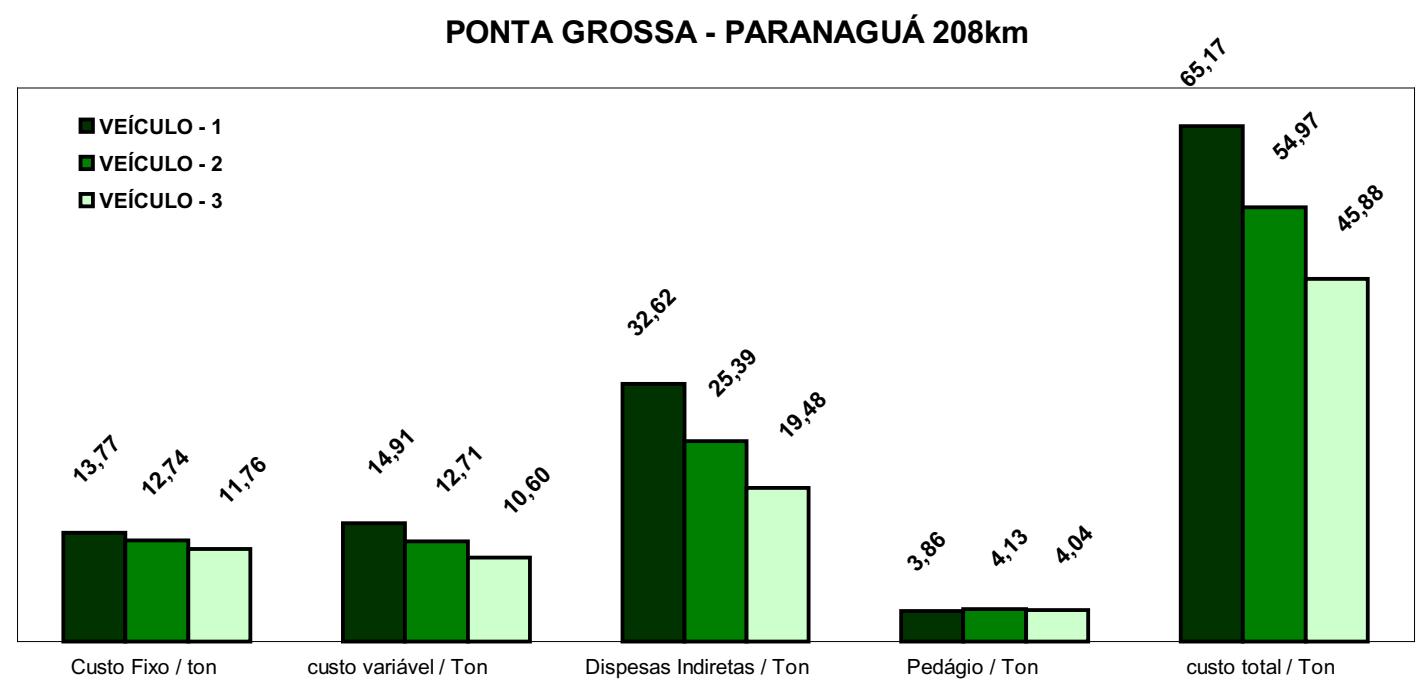

Figura 4. Custo por tonelada transportada no trecho entre Ponta Grossa - Paranaguá.

\section{Análises dos resultados}

Em todas as simulações realizadas para os três tipos diferentes de veículo, o veículo 3 apresenta as melhores relações econômicas, quando considerase o custo unitário por tonelada transportada.

Com relação à carga transportada por mês, nas três simulações, o veículo 3 apresenta uma capacidade de transporte de carga bastante superior aos outros dois veículos. O veículo 3 transporta cerca de $67 \%$ a mais de carga por mês que o veículo 1 e $30 \%$ a mais que o veículo 2 .

Outro ponto importante é a distância percorrida, observa-se que, quanto maior a distância percorrida por cada veículo, menor será o custo total por tonelada por quilômetro. Mesmo com um aumento dos custos de pedágio, que acontece devido a uma distribuição não uniforme das praças de pedágio no decorrer dos percursos utilizados neste estudo de caso, os custos diminuem com o aumento das distâncias. Isso ocorre, pois o aumento da distância exerce maior influencia no valor final dos custos por tonelada por quilômetro que o aumento do custo de pedágio.

Por último, apresenta-se um gráfico relacionando os custos por tonelada por quilômetro, em função das distâncias percorridas por cada veículo. 
CUSTOS X DISTÂNCIA

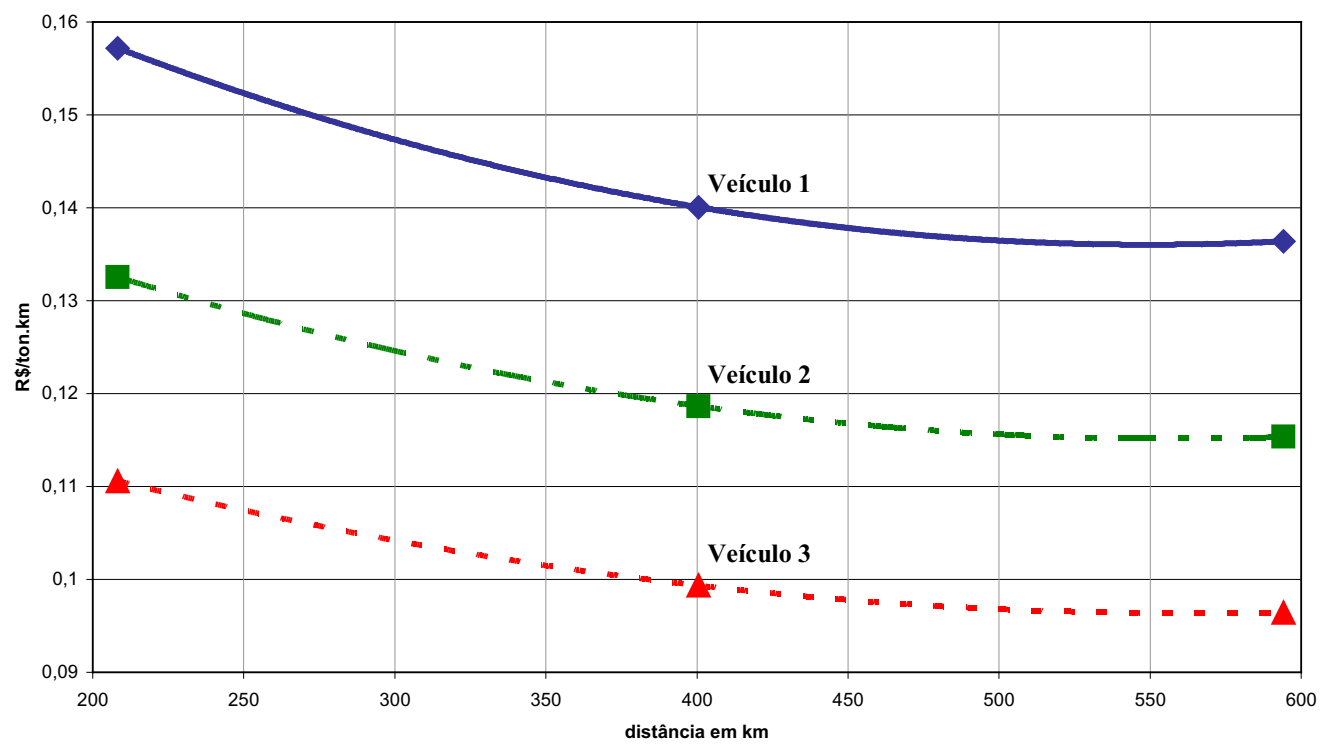

Figura 5. Custos por tonelada por quilômetro em função da distância percorrida por veículo.

\section{Conclusões}

Os resultados das simulações efetuadas mostram que existe uma grande diferença no cálculo de custos em função do tipo de veículo utilizado e da distância percorrida.

Conclui-se, com base nos resultados obtidos, pela superioridade do veículo 3 (rodotrem graneleiro) sobre os outros veículos, veículo 1 (semi-reboque graneleiro) e veículo 2 (bi-trem graneleiro), tanto em relação aos custos quanto à capacidade de carga, fato que o torna econômicamente mais indicado para o transporte rodoviário de carga a granel.

Em relação aos custos totais de transporte por tonelada, o veículo 3 apresenta valores cerca de $29 \%$ inferiores ao veículo 1 e cerca de $17 \%$ inferiores ao veículo 2 .

Já no que diz respeito ao peso de carga transportada o veículo 3 transporta cerca de $67 \%$ a mais de carga por mês que o veículo 1 e $30 \%$ a mais que o veículo 2 .
Fica, portanto, claramente comprovada a eficiência do veículo 3 sobre os outros dois analisados no transporte de grãos: com a utilização deste veículo, ganha-se em capacidade e em redução de custos de transporte.

\section{Referências}

AGÊNCIA NACIONAL DE TRANSPORTES TERRESTRES - ANTT. Registro Nacional de Transportadores Rodoviários de Carga-RNTRC. 2006. Disponível em: $\quad<$ http://www.antt.gov.br/rntrc/rntrc numeros/rntrc veiculo.asp $>$. Acesso em: 12 jun. 2006.

ASSOCIAÇÃO NACIONAL DO TRANSPORTE DE CARGAS - NTC. Manual de Cálculo de Custos e Formação de Preços do Transporte Rodoviário de Cargas. 2001.Disponível em: <http://www.guiadotrc. com.br/pdfiles/manual.pdf $>$. Acesso em: 20 jun. 2006.

ASSOCIAÇÃO NACIONAL DO TRANSPORTE DE CARGAS E LOGÍSTICA - NTC. Perfil do Transporte Rodoviário de Cargas. 2006. Disponível em: $<\underline{\text { http:// }}$ www.ntc.org.br>. Acesso em: 4 abr. 2006.

BOZZA, G. M.; DIGIOVANI, M. A. Escoar a safra sai pela metade do preço nos EUA. Curitiba: Federação da Agricultura do Estado do Paraná, 2004. (Boletim 
Informativo, n. 844). Disponível em: <http://www.faep. com.br/boletim/bi844/pag11bi844.htm $>$. Acesso em: 2 de abr. 2006.

DEPARTAMENTO DE ESTRADAS DE RODAGEM DO PARANÁ - DER. Concessões Rodoviárias. Preços das Tarifas Praticadas. 2006. Disponível em: <http:// www.pr.gov.br/derpr>. Acesso em: 24 ago. 2006.

UNITED STATES DEPARTMENT OF AGRICULTURE - USDA. Banco de Dados. 2006. Disponível em: $<\underline{\text { http:// }}$ www.usda.gov/wps/portal/usdahome $>$. Acesso em: 8 de out. 2006. 